Manuscript received December 6, 2015; accepted for publication May 27, 2016; published online June 10, 2017.

College of River and Ocean Engineering, Chongqing Jiaotong Univ., 66, Xuefu Road, Nan'an District, Chongqing, 400074, P.R.China

${ }^{2}$ Dept. of Hydrology and Atmospheric Sciences, The University of Arizona, 1133 E. James E. Rogers Way, 122 Harshbarger Bldg 11, Tucson, AZ 85721

${ }^{3}$ Key Laboratory of Ministry of Education for Geomechanics and Embankment Engineering, Hohai Univ., Nanjing, China (Corresponding author),

zhayuan87@whu.edu.cn

${ }^{4}$ State Key Laboratory of Water Resources and Hydropower Engineering Science, Wuhan Univ., Wuhan, China
Y. Liang, ${ }^{1,2,3}$ C. Zeng, ${ }^{1}$ J.-J. Wang, ${ }^{1}$ M.-W. Liu, ${ }^{1}$ T.-C. Jim Yeh, ${ }^{2}$ and Y.-Y. Zha ${ }^{2,4}$

\section{Constant Gradient Erosion Apparatus for Appraisal of Piping Behavior in Upward Seepage Flow}

\section{Reference}

Liang, Y., Zeng, C., Wang, J.-J., Liu, M.-W., Jim Yeh, T.-C., and Zha, Y.-Y., "Constant Gradient Erosion Apparatus for Appraisal of Piping Behavior in Upward Seepage Flow," Geotechnical Testing Journal, Vol. 40, No. 4, 2017, pp. 630-642, http://dx.doi.org/10.1520/GTJ20150282. ISSN 0149-6115

\section{ABSTRACT}

Seepage direction is crucial for understanding the critical state and development of piping erosion. A stress-controlled apparatus was designed to investigate the piping behavior of cohesionless soil under upward flow condition. The components of the new apparatus included a loading chamber, a vertical and confining loading system, an upstream water supply device, a soil-water separating system, and a water collecting system. The loading chamber provides space for a soil specimen setting and loading. The combination of a vertical and a confining loading system was designed to apply complex stresses to a soil specimen. Under the stresses, the specimen was then eroded by the gradually increasing hydraulic head supplied by the water supply system. The eroded particle and spilling water were collected and detected by the soil-water separating system and the water collecting system. A series of experiments were carried out using the new apparatus. Results demonstrated the repeatability experiments and usefulness of the apparatus. The new apparatus allowed us to investigate the piping behavior under different stress states and hydraulic gradients. With this new apparatus and experiments, we found that lower and high critical hydraulic gradients (CHGs) should be included as the criteria of piping development based on the relationship between the hydraulic gradient and the seepage response. In addition, the stress state on the CHG and the particle erosion rate played important roles in the piping development. The outer pressure on the specimen can retard the development of erosion. In contrast, the hydraulic gradient was found to be positively correlated to the erosion rate. Results also indicated that a specimen would collapse once the amount of eroded small particles exceeds the critical value of $46.5 \%$ of the soil.

\section{Keywords}

piping, stress-controlled apparatus, critical hydraulic gradient, erosion rate 


\section{Introduction}

Piping is one of the most common causes of failures in hydraulic structures, including earth dams, dikes, and levees. Previous research shows that piping is responsible for approximately half of all dam failures worldwide (Foster et al. 2000). Richards and Reddy (2007) provided a review of studies of piping phenomena and they classified piping phenomena into five categories, namely, backward erosion, internal erosion, tunneling, suffusion, and heave. Richards and Reddy (2012) reported that a third of all piping failures can be attributed to backward erosion piping, which includes piping through embankments and under impervious earthen dams or levees.

Studies of piping and other seepage erosion can be dated back to the early 1900s. Pioneering studies mainly concentrated on the criteria for assessing seepage erosion. Bligh $(1910,1913)$ proposed an empirical relationship between piping potential and the shortest flow path length beneath a water-retaining structure. This empirical theory is often termed the line of creep theory, which was later extended by Lane (1934) to investigate the critical state of piping. Terzaghi (1922) was the first to use a critical value of hydraulic head to describe the critical state of cohesionless soil, which is the origin of the critical hydraulic gradient (CHG) criterion that is still being employed (Chang and Zhang 2011, 2012, 2013; Indraratna and Vafai 1997; Indraratna and Radampola 2002; Skempton and Brogan 1994). Besides the CHG criterion, critical shear stress criteria were proposed to determine the critical state of dispersive soil (Wan and Fell 2004a,2004b,2008).

Recently, researchers have begun to focus on the erosion process and erosion rate of fine particles in piping beside the critical state. For example, Sterpi (2003) carried out laboratory experiments to investigate the erosion of fine particles from soil samples subjected to controlled seepage flow. Erosion rate represents the speed of particle loss, which indicates the potential severity of the piping development. As a matter of fact, the erosion rate is an indispensable parameter in the piping mathematical models, which have been used to describe the piping process and to predict the seepage failure (e.g., Cividini and Gioda 2004; Liang et al. 2013). Thus, erosion rate is also a vital characteristic of piping development in addition to the critical hydraulic state, such as the CHG. The characteristics of piping development, including the critical state criteria and the erosion rate, are related to intrinsic properties of soils, such as particle size distribution (PSD), particle unit weight, geometric factors, and fine particle content (Fleshman and Rice 2013, 2014; Kovacs 1981; Moffat and Fannin 2006; Skempton and Brogan 1994; Sterpi 2003).

Over the past few years, a considerable number of laboratory experiments have shown that external factors, such as stress state and compactness, are also vital to piping behavior (Chang and Zhang 2011, 2012, 2013; Fleshman and Rice 2014;
Luo et al. 2013a, 2013b, 2014; Richards and Reddy 2010). These investigations on piping erosion have led to the development of various advanced test apparatus, including constant gradient piping test apparatus (Fleshman and Rice 2013), stresscontrolled erosion apparatus (Chang and Zhang 2011; Luo et al. 2013a, 2013b), and true triaxial piping test apparatus (Richards and Reddy 2010), all of which have played key roles in piping erosion studies.

Besides the intrinsic and external factors mentioned above, the flow direction in seepage field is also an important factor in piping development. Self-gravity can enhance seepage erosion if the angle between the directions of gravity and flow is acute. Otherwise, gravity prevents the development of the erosion. Generally speaking, CHG is maximal at the piping outlet because the seepage flow here is upward and opposite to the direction of gravity. This fact suggests that the hydraulic conditions at the outlet are the ultimate control for piping development. Thus, understanding of the piping behavior near the piping outlet, where the seepage is upward, is crucial to evaluate the piping erosion in practice. However, this behavior has been generally neglected in previous studies. In this paper, we design a new stress-controlled apparatus to investigate the piping behavior under upward flow conditions with different constant hydraulic gradients. We use this new apparatus to investigate the CHG, particle erosion phenomena, and the stress-strain behavior in the piping development under different stress states.

\section{Test Apparatus}

The new designed apparatus for conducting piping erosion experiments is shown in Fig. 1. The apparatus is composed of a loading chamber, a vertical loading system, a confining loading system, an upstream water supply system, a soil-water separating system, and a water collecting system. The loading chamber is a hollow cylindrical tank composed of a cover plate, a bottom plate, and an acrylic tube. The cover and bottom plates, with thickness equal to $10.0 \mathrm{~mm}$, are made of stainless steel. The inner diameter, height, and thickness of the acrylic tube are 400.0, 300.0, and $8.0 \mathrm{~mm}$, respectively. The plates and the acrylic tube are separable, and are fixed together with bolts when experiments are carried out. O-rings are used on the connections between the plates and the tube to seal the chamber. In the chamber, a hollow base pedestal for specimen setting is fixed on the center of the bottom plate. The specimen, with a diameter of $100.0 \mathrm{~mm}$ and a height of $200.0 \mathrm{~mm}$, is installed on the base pedestal. The base pedestal, the top cap on the specimen, and a rubber film are utilized to isolate the specimen in the loading chamber (Fig. 2a). Aside from bearing the specimen, the hollow steel base pedestal also provides a bottom buffer for the upstream flow. Given the generally high permeability of the test soil, the commonly used porous stone in the conventional triaxial test cannot be adopted because a significant head loss 
FIG. 1

Sketch map of the new designed apparatus.

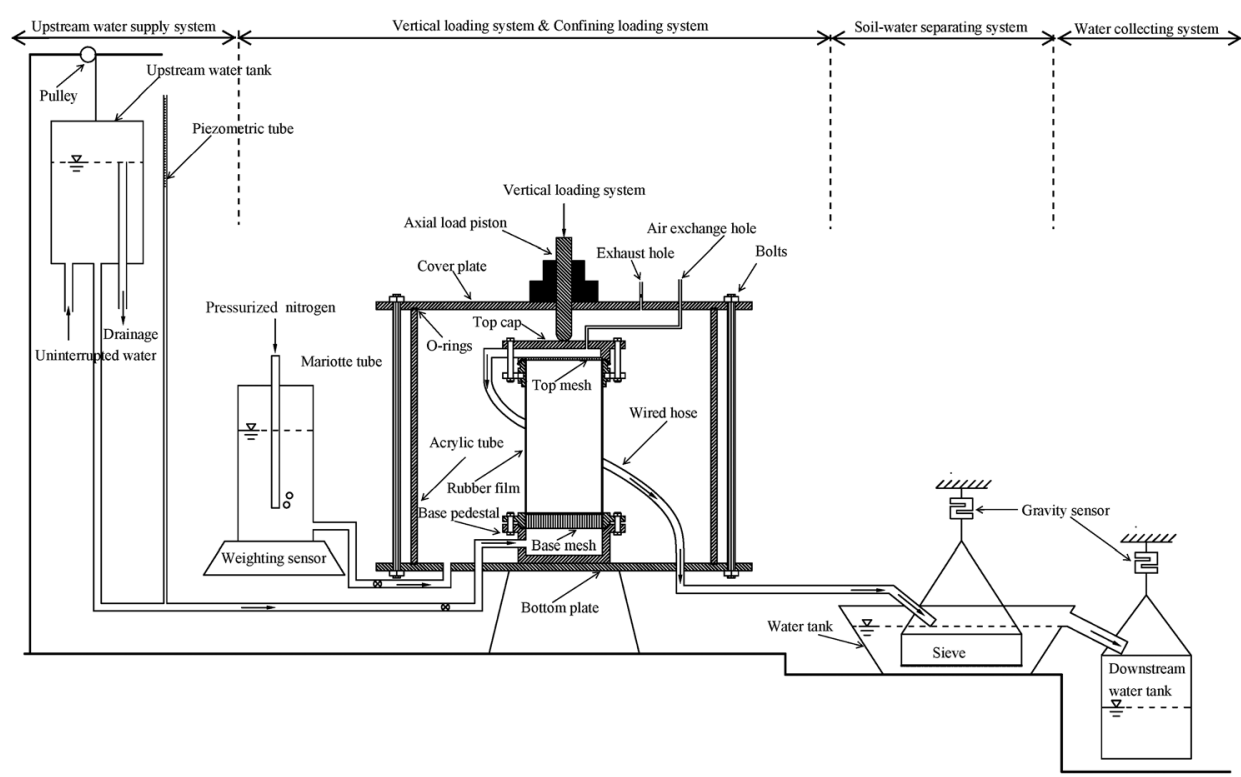

will be induced. Hence, a perforated plate, labeled as base mesh in Fig. $\mathbf{2 b}$, is placed in the base pedestal to bear the specimen and provide uniform flow. The base mesh, with a diameter of $96.0 \mathrm{~mm}$ and a height of $20.0 \mathrm{~mm}$, is made of aluminum. The diameter of the holes in the base mesh is $5.0 \mathrm{~mm}$, and the interval between the centers of two holes is $6.0 \mathrm{~mm}$ (Fig. 2b). Moreover, a steel wire sieve with $75.0 \mu \mathrm{m}$-sized holes is utilized to prevent the fine particles in the specimen from falling into the base pedestal. The top cap on the specimen is also steel and hollow. A steel top mesh with the same holes as the base mesh is set on the specimen top to provide an exit for the flowing water and eroded particles. The inner diameter of the top cap is slightly smaller than the diameter of the top mesh, so that the vertical load on the top cap can be applied on the specimen via the top mesh (Fig. 2a).

An upstream water supply system is designed to support constant head water for the experiments. In this system, uninterrupted water is delivered into a rectangular tank and discharged through an unadjustable exit (Fig. 1). Moreover, a water pipe connects the bottom of the water tank and the water inlet
FIG. 2

Installation of setting and isolating of the specimen: (a) detailed profile map of components for specimen installing and (b) picture of the base pedestal and the aluminum.

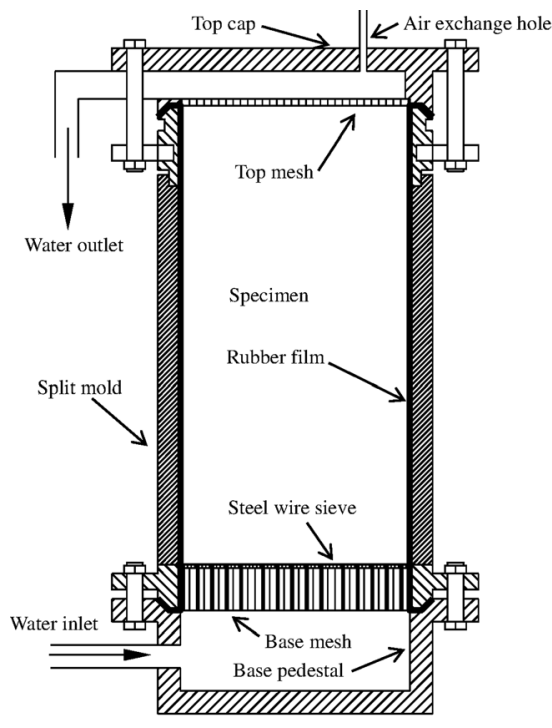

(a)

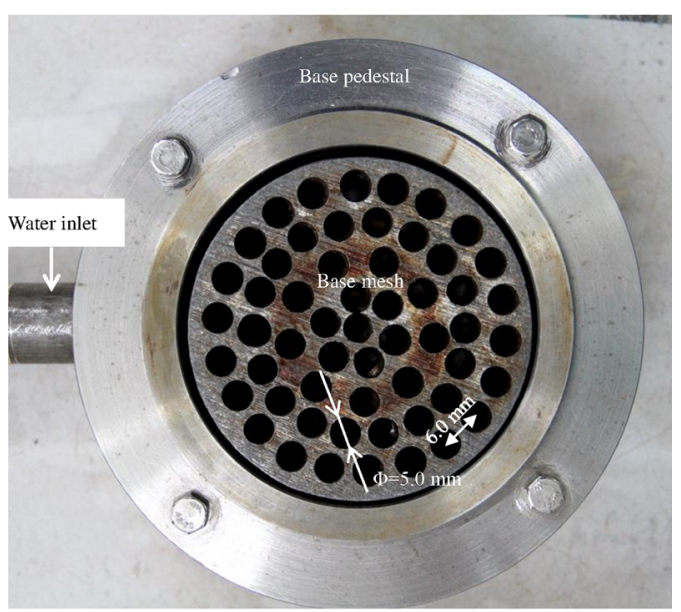

(b) 
on the base pedestal under the specimen. A constant upstream hydraulic head is then applied on the bottom of the specimen if the altitude of the water tank is fixed. The value of the head is monitored by a piezometric tube. On the other hand, since the water through the specimen spills freely on top of the specimen, the hydraulic head on the specimen top can be treated as a constant equal to the altitude of the spilling water surface. This means that the head difference applied on the specimen is constant if the upstream head is maintained, as intended in the design of the apparatus. The head difference is variable by adjusting the altitude of the upstream water tank. A manual winch and a pulley are employed to control the location of the water tank. Thus, the upstream water supply system can support different constant hydraulic gradients to the specimen to satisfy different experimental requirements.

In the piping process, the eroded particles and water flow out of the top mesh on the specimen and are separated by a soil-water separating system. A sieve immersed in a water tank of the system takes in the mixture of liquid and solid particles, and catches the eroded particles on the sieve screen. The water level in the water tank is maintained constant due to an outlet on the tank draining water continuously. The buoyant weight of the accumulated eroded particles and the sieve itself is measured and continuously transmitted to the center computer with a gravity sensor. The detecting range and the precision of this gravity sensor are $1000.0 \mathrm{~g}$ and $1.5 \mathrm{~g}$, respectively. The amount of eroded particles is calculated using the relation between dry weight and buoyant weight of the particles. The water filtered out of the soil-water separating system flows into a water collecting system, which is adopted to monitor the varying fluxes through the specimen. The weight of the water tank in the water collecting system is recorded with another gravity sensor. The detecting range and the precision of this gravity sensor are 5000.0 and $7.5 \mathrm{~g}$, respectively. The seepage flux is calculated by differentiating the relation between the accumulative weight of collected water and the time through the data received by the computer from the sensor.

The stress state for the experiments is applied by vertical and confining loading systems. The vertical loading system includes a servo compression tester and a controlling unit (Fig. 3). The tester can supply a constant vertical load, with a precision equal to $7.5 \mathrm{~N}$, to the top of the steel cap on the specimen. The load is transferred to the top of the specimen by the rigid screen between the steel cap and the specimen. The tester is capable of automatically recording the vertical displacement of the specimen top with a precision equal to $0.01 \mathrm{~mm}$. The displacement is serviceable to evaluate the vertical strain of the specimen in the particle erosion process. The confining loading system, which is shown in Fig. 1, applies constant normal stress to the side and top of the specimen with a precision equal to $0.25 \mathrm{kPa}$. The system comprises a nitrogen cylinder, pressure maintaining valves, and a gas-liquid exchange tank. The gas-liquid exchange tank is made of poly(methyl methacrylate) (PMMA) and has a Mariotte tube fixed in it. The nitrogen cylinder connects the Mariotte tube to a plastic pipe and pressure maintaining valves. The pressure maintaining valves are used to control the air pressure supplied to the gas-liquid exchange tank with the precision of $0.05 \mathrm{kPa}$. Since the air

\section{FIG. 3}

Servo compression tester and controlling unit of the vertical loading system.

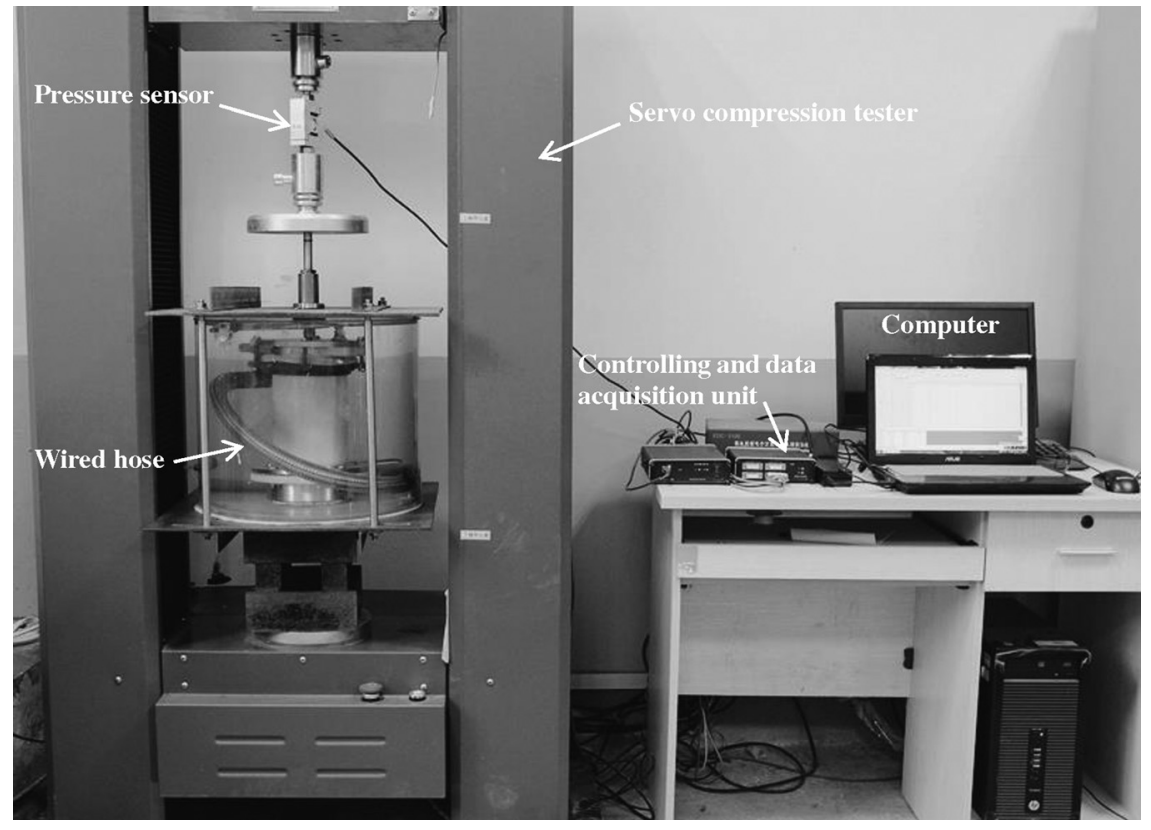


pressure flowing into the Mariotte tube is constant, the water out of the gas-liquid exchange tank is constant as well, meaning that the confining loading system provides constant water pressure to the specimen. Besides applying the confining load, another important function of the confining loading system is to evaluate the volumetric strain of the specimen. This evaluation is achieved by monitoring the weight varying of the gas-liquid exchange tank with a weighting sensor. Combining the vertical strain detected by the vertical loading system leads to the radial strain of the specimen as follows (Das 2013):

$$
\varepsilon_{r}=\frac{\varepsilon_{V}-\varepsilon_{h}}{2}
$$

where:

$\varepsilon_{r}=$ radial strain,

$\varepsilon_{V}=$ volumetric strain detected by the confining loading system, and

$\varepsilon_{h}=$ vertical strain detected by the vertical loading system.

The stress state reflects the buried depth of the soil in practice. The vertical stress, namely the major principal stress, can be calculated based on the effective gravity and the depth of the soil. The minor and medium principal stresses can be determined using the static lateral pressure coefficient of the layer. In this study, the confining stress is equal to the minor and medium principal stresses. And the vertical stress applied by the vertical loading system is equivalent to the deviatoric stress. Considering the effect of the confining pressure on the bottom of the piston rod, the load applied by the vertical loading system should be

$$
F=\frac{p A}{K_{0}}+p A^{\prime}=\frac{p A}{1-\sin \varphi}+p A^{\prime}
$$

where:

$F=$ load applied by the vertical loading system,

$p=$ confining pressure,

$A=$ cross-sectional area of the specimen,

$A^{\prime}=$ cross-sectional area of the piston rod transferring the vertical load,

$K_{0}=$ static lateral pressure coefficient, and

$\varphi=$ friction angle of the tested soil.

Compared to the present stress-controlled apparatus, the design in this study still faces two difficulties affecting the feasibility of the tests. The first one is how to connect the outlet on the top cap of the specimen out of the confining room. On the one hand, the connecting pipe should have a certain rigidity to avoid great deformation and maintain sufficient delivery capacity under the confining pressure. On the other hand, it should be soft enough to deform with the top of the specimen and simultaneously avoid disturbing the stress state applied on the specimen. After several attempts, a wired hose is chosen for the apparatus. The hose is made of thermoplastic polyurethane and steel wire. The radial rigidity of this hose is very high, while the longitudinal rigidity is low, meaning it is easy to be bent. If the pipe spirals around the specimen from the outlet of the top cap on the specimen to the outlet on the bottom of the confining chamber (Fig. 2), its disturbance on the stress distribution on the specimen top is proved to be negligible and acceptable. Such design is effective in eliminating the influences of the pipe on accuracy and reliability of the tests by means of lowering the disturbance and maintaining the drainability of the pipe in the confining chamber. Another difficulty is the possibility of siphonage in the pipe out of the specimen. The flow direction in the pipe is downward, and thus siphonage will occur if the flowing water occupies the whole cross section of the pipe. Siphonage will lead to a sudden and great drop of the hydraulic head, resulting in instant soaring of the hydraulic gradient. The unwanted variation of the hydraulic gradient will likely lead to the experiment failure. To avoid siphonage, the hollow in the cap is connected to the outside of the chamber with a plastic tube. This tube insures atmospheric pressure balance in and out of the top cap, which means that the downstream head on the specimen can remain stable throughout the testing process.

\section{Soil Specimen Preparation}

Soil used for specimen preparation was obtained from beach land of the Yangtze River in Chongqing, China. The soil was first washed to eliminate impurities, and then transferred to a $75 \mu \mathrm{m}$ sieve to exclude the clay fraction with a particle diameter less than $75 \mu \mathrm{m}$. The particles that remained on the sieve were transferred to a ceramic vessel and dried in an oven at $110^{\circ} \mathrm{C}$. The dried soil was then separated into a series of fractions with the aid of $10,5,2,1,0.5,0.25$, and $0.075 \mathrm{~mm}$ sieves. In the study, the coarse particles, which remained on the 5,2 , and $1 \mathrm{~mm}$ sieves, and the fine particles, which remained on the $0.075 \mathrm{~mm}$ sieve, were selected and mixed to produce the specimens used for the experiments. The PSD is shown in Fig. 4, and the physical properties of the soil used for the tests are summarized in Table 1.

Unlike the specimens made up of cohesive soil, the specimens used in this study are unlikely to be transferred without disturbance from a sample mold into the confining chamber because the soil is incoherent. Thus, specimens are prepared directly in the chamber to avoid disturbance. The first step of preparation is to seal the rubber membrane, which is carefully inspected prior to use, to the specimen base. Extruding method, rather than the traditional rubber O-ring method, is adopted to seal the rubber membrane at the cap and base of the specimen to achieve a better sealing effect. Through extrusion, one end of the rubber membrane is set between the base and the lower ring of the apparatus and tightly extruded with four bolts. Prior to sealing the up end of the rubber membrane, a split mold with an upper ring is installed on the base pedestal. The up end of the rubber membrane is temporarily rolled onto the upper ring 
FIG. 4 Particle size distribution (PSD) of the soil used for the specimen preparation.

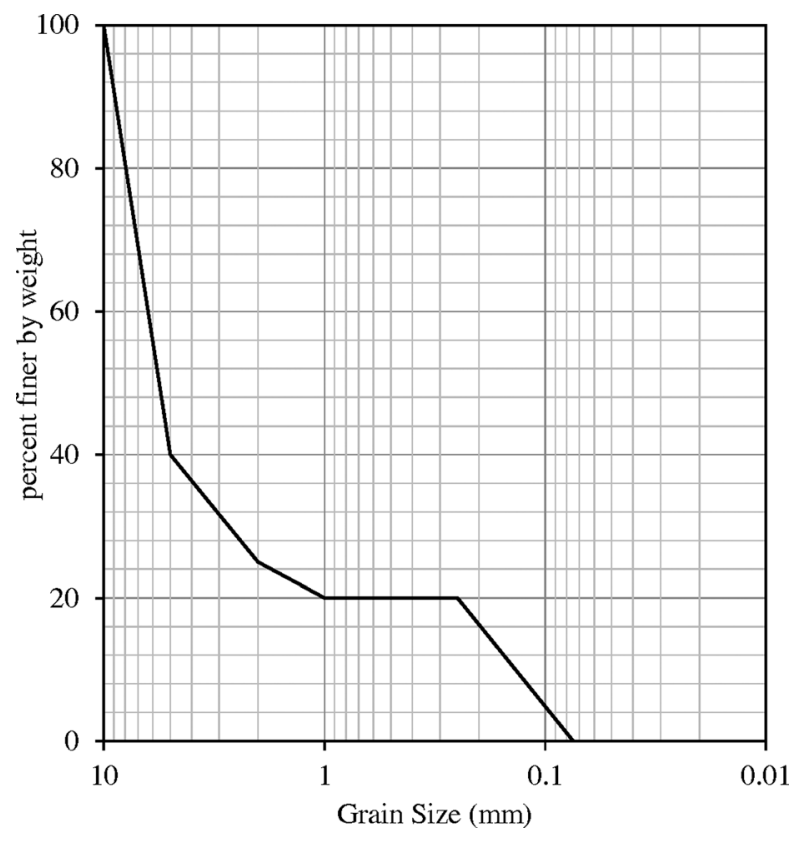

during specimen preparation. The second step is to tamp soil in the rubber membrane. The base mesh and the steel wire sieve are set in the hollow of the base pedestal prior to soil tamping. A negative pressure is applied on the split mold to ensure the rubber membrane tightly attaches to the inner wall of the mold when the soil is tamped. The soil, which is thoroughly mixed with a water content equal to $4.0 \%$, is tamped in the split mold in eight layers. The weight of the soil used for each layer is prepared in advance based on a target dry density (i.e., $1850 \mathrm{~kg} / \mathrm{m}^{3}$ ). The third step is to install the top cap on the specimen. The top mesh and the top cap are set on the top of the specimen after tamping the soil to a target altitude. Then joint the cap and the top ring with four bolts to seal the up end of the rubber membrane using the extruding method. The last step in

TABLE 1 Physical properties of the soil used in the study.

\begin{tabular}{lc}
\hline Physical Property & Value \\
\hline Maximum dry density, $\rho_{d \max }\left(\mathrm{kg} / \mathrm{m}^{3}\right)$ & 2010 \\
Minimum dry density, $\rho_{d \min }\left(\mathrm{kg} / \mathrm{m}^{3}\right)$ & 1695 \\
Optimum water content, $w_{\mathrm{opt}}(\%)$ & 4.01 \\
Characteristic size, $d_{10}(\mathrm{~mm})$ & 0.13 \\
Characteristic size, $d_{30}(\mathrm{~mm})$ & 2.6 \\
Mean particle size, $d_{50}(\mathrm{~mm})$ & 5.4 \\
Characteristic size, $d_{60}(\mathrm{~mm})$ & 6.2 \\
Coefficient of curvature, $C_{c}$ & 8.4 \\
Coefficient of uniformity, $C_{u}$ & 47.7 \\
Specific gravity, $G_{s}$ & 2.67 \\
\hline
\end{tabular}

specimen preparation is to remove the split mold. To ensure the stability of the specimen, the confining chamber is filled with distilled water to the level of the top of the specimen before the mold is removed.

\section{Apparatus Mounting}

After the specimen preparation, the outlet on the specimen cap is connected out of the confining chamber with the wired hose. The confining chamber is then covered with the top plate after linking the air exchange holes on the specimen cap to the top plate. The confining chamber then is sealed by tightening the screws connecting the top plate and the base plate. Subsequently, the axial load piston is brought into contact with the specimen cap several times to permit proper seating and alignment of the piston and cap. Afterward, the confining loading system, upstream water supply system, soil-water separating system, and water collecting system are connected to the confining chamber. This chamber is filled with distilled water through the exhaust valve on the top plate opened prior to the saturation. Care must be taken to avoid trapping air or leaving an air space in the chamber, and the exhaust valve is ensured to be closed when water overflows from it.

\section{Test Procedure}

\section{SATURATION}

Saturation is the primary process to drive out air and fill all voids in the specimens with water for every test. The upstream water supply system is adopted to accomplish saturation in the experiments by slowly and continually filling water into the base pedestal. Accordingly, the voids in the specimen are replaced by water as the water level rises. The rising rate of water level is controlled at about $2.0 \mathrm{~mm} / \mathrm{min}$ to prevent seepage deformation in this stage. Water filling is terminated when the water level reaches the top of the specimen. Saturation is then continued as the specimen is left to stand for another $4.0 \mathrm{~h}$.

\section{APPLICATION OF STRESS STATE}

After saturation, the specimen is consolidated by applying the target confining stress and vertical stress prior to the erosion testing. The proposed stress states are applied to the specimen by controlling the output of the confining loading and vertical loading systems. The confining stress, which increases gradually at a rate of $2.0 \mathrm{kPa} / \mathrm{min}$, is applied prior to the vertical stress. The vertical stress, if needed, is applied after the confining stress reaches the proposed value. The specimen is consolidated under the stress state for $2.0 \mathrm{~h}$. The volumetric strain generated in the application and consolidation of stress state is constantly monitored by the confining loading system. The strain is then used 
TABLE 2 Information of tests carried out in the study.

\begin{tabular}{|c|c|c|c|c|c|}
\hline \multirow[b]{2}{*}{ Test Number } & \multirow[b]{2}{*}{ Confining Pressure $(\mathrm{kPa})$} & \multicolumn{2}{|c|}{ Stress State } & \multirow[b]{2}{*}{ Final Dry Density $\left(\mathrm{g} / \mathrm{cm}^{3}\right)$} & \multirow[b]{2}{*}{ Final Hydraulic Gradient } \\
\hline & & Effective Mean Stress (kPa) & Deviatoric Stress $(\mathrm{kPa})$ & & \\
\hline TS-1 & 20 & 20 & 0 & 1.853 & 0.80 \\
\hline TS-2 & 20 & 20 & 0 & 1.852 & 0.80 \\
\hline TS-3 & 10 & 10 & 0 & 1.854 & 0.77 \\
\hline TS-4 & 20 & 29 & 27 & 1.858 & 0.78 \\
\hline TS-5 & 30 & 43.3 & 40 & 1.859 & 0.83 \\
\hline TS-6 & 20 & 29 & 27 & 1.856 & 0.88 \\
\hline TS-6R & 20 & 29 & 27 & 1.856 & 0.88 \\
\hline TS-7 & 20 & 29 & 27 & 1.859 & 0.98 \\
\hline TS- 8 & 20 & 29 & 27 & 1.857 & 1.08 \\
\hline TS-9 & 40 & 57.7 & 53 & 1.871 & 1.10 \\
\hline TS-9R & 40 & 57.7 & 53 & 1.87 & 1.10 \\
\hline
\end{tabular}

to calculate the initial compaction degree of the erosion testing. The final dry density under the stress state before testing is shown in Table 2.

\section{EROSION TESTING}

After the initial consolidation under the stress state, the upstream water supply system is employed to provide pressurized water to the bottom of the specimen by elevating the upstream water tank gradually. The increased upstream head contributes to the simultaneous increase of the hydraulic gradient in the specimen. In the initial stage before piping occurs, the rising rate of the upstream head is controlled at $1.0 \mathrm{~cm}$ per $10 \mathrm{~min}$ stepwise, meaning that the increasing rate of the hydraulic gradient is 0.05 per $10 \mathrm{~min}$. Once the hydraulic gradient arrives at a critical value at which the piping erosion occurs, the upstream head is instantly elevated to a proposed height to detect the erosion behaviors under this hydraulic gradient. Three tests, TS-6, TS-7, and TS- 8 in Table 2, with the same specimens and stress states are carried out under different hydraulic gradients to reveal the reflections of the erosion behaviors.

In the erosion process, the eroded particles are filtered from the spilling water by the soil-water separating system. The gravity sensor detects the buoyant weight of the accumulated particles every $1.0 \mathrm{~s}$. The dry weight of the eroded particles is calculated as follows:

$$
g_{s}=\frac{\gamma_{s}}{\gamma_{s}-\gamma_{w}} g_{b}
$$

where:

$g_{s}=$ dry weight of the accumulated eroded particles,

$g_{b}=$ buoyant weight of the accumulated eroded particles detected by the gravity sensor, and

$\gamma_{s}$ and $\gamma_{w}=$ unit weights of the eroded particles and water, respectively.
The flux through the specimen is detected by a gravity sensor connecting to the downstream water tank. The change rate of the flux reflects the varying permeability of the specimen, which is essential in particle erosion analyses. The volumetric strain of the specimen is monitored with the confining loading system by detecting the weight fluctuation of the water in the gas-liquid exchange tank. In addition, the vertical strain is solved by the vertical loading system, which records the displacement of the specimen top.

\section{Test Results}

\section{TYPICAL RESULTS AND REPEATABILITY}

Typical test results are illustrated in Fig. 5, including the erosion behaviors detected in tests TS-1 and TS-2. Fig. 5a displays the changing seepage velocity of the flow through the specimen due to the application of a gradually increasing hydraulic gradient. The curves of velocity are approximately linear in the beginning and then the velocity increase is accelerated. Even when the hydraulic gradient is maintained at 0.8 , the seepage velocities still increase with time, indicating that the permeability is still soaring as the particles are eroded. The erosion can be evaluated based on the quantity of fine particles collected by the soil-water separating system (Fig. 5b). The eroded particles are initially collected by the soil-water separating system when the test time is $120.0 \mathrm{~min}$ and the corresponding hydraulic gradient is 0.605 . At this time, a few of particles are brought out of the specimen. The quantity of accumulative particles is negligible as the hydraulic gradient is elevated to 0.8 at 140.0 min rapidly. Thus, Fig. 5b mainly clarifies the variation of accumulated eroded particles in the test procedure with a constant hydraulic gradient equal to 0.8 for TS- 1 and TS-2. Under this hydraulic gradient, the accumulated eroded particles remarkably soar at the beginning of the erosion, and subsequently the erosion rate declines to a relatively static level. The 
FIG. 5

Testing results and repeatability assessment: (a) Varying of seepage velocity; (b) Varying of eroded particles; (c) Varying of volumetric deformation; and (d) Coefficient of variations (CVs) of eroded particle quantity and volumetric deformation.
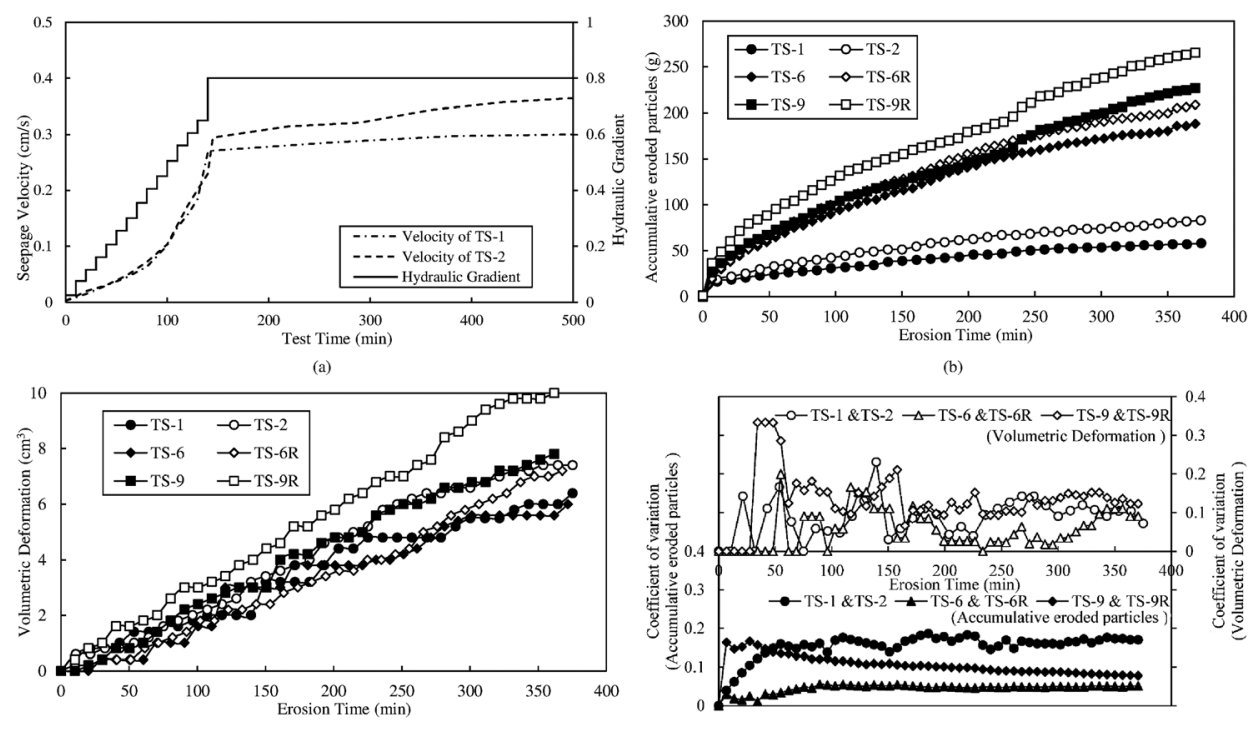

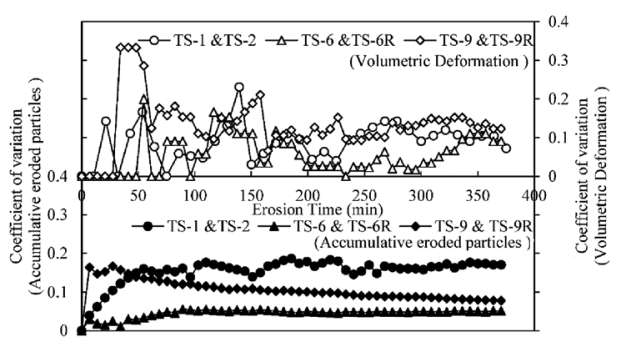

quantity of accumulated eroded particles grows gradually and tends to be constant when the test time exceeds $450.0 \mathrm{~min}$, which indicates the nonlinear relations between the erosion particles and the erosion time. Sterpi (2003) carried out a series of erosion tests and proposed an empirical law to describe the process of fine particle erosion. The law demonstrates the logarithmic relations between erosion quantity and erosion time, which is well coincident with the results shown in Fig. $\mathbf{5 b}$. The loss of fine particles gives rise to the volumetric deformation of the specimens. The volumetric deformation is recorded with the confining loading system by detecting the weight change of the gas-liquid exchange tank. The data on volumetric deformation are converted from the recording of the weight sensor and shown in Fig. 5c. The figure illustrates that the volume of specimens shrinks gradually with the increased erosion of soil.

Fig. 5 also implies a high degree repeatability of the test and the apparatus through a comparison of the test results. In addition to the tests TS- 1 and TS-2, more cases, TS- 6 , TS6R, TS-9, and TS-9R, give a supplementary demonstration about the repeatability of the test. TS-6R and TS-9R are tested under similar conditions to those of TS- 6 and TS-9, shown in Table 2. The test results of variations of accumulative eroded particles and volumetric deformation are also plotted in Figs. 5b and $\mathbf{5 c}$. In order to evaluate the accuracy of the observed repeatability, a statistic parameter, the coefficient of variation $(\mathrm{CV})$, is employed to quantify the dispersion of the tests. It is defined as

$$
C V=\frac{\sigma}{\mu}
$$

where:

$C V=$ the coefficient of variation,

$\sigma=$ the standard deviation, and

$\mu=$ the mean value.

The CVs of the accumulative eroded particles and volumetric deformation in the repeating tests are shown Fig. 5d. As to the accumulative eroded particles, the CVs vary smoothly with erosion time and tend toward constant values. The CV in test group TS-1 \& TS-2 is a little higher, which is 0.17 (or $17.0 \%$ ), whereas in other test groups the CVs are no more than 0.1 (or $10.0 \%$ ). Regarding the volumetric deformation, the CVs are more dispersed than those of the accumulative eroded particles. But they are underneath 0.2 (or $20.0 \%$ ) as well except some points in the beginning of the erosion. The mean values of the CVs in the accumulative eroded particles for test groups TS-1 \& TS-2, TS-6 \& TS-6R, and TS-9 \& TS-9R are 0.15 (or $15.0 \%$ ), 0.046 (or $4.6 \%$ ), and 0.1 (or $10.0 \%$ ), respectively. The mean values of the CVs in the volumetric deformation for test groups TS-1 \& TS-2, TS-6 \& TS6R, and TS-9 \& TS-9R are 0.097 (or $9.7 \%$ ), 0.064 (or $6.4 \%$ ), and 0.13 (or $13.0 \%$ ), respectively. In terms of the repeatability experiments carried out by Richards and Reddy (2010), a CV less than $10.0 \%$ can be used as the criterion of repeatability. It shows that the CVs in this study are almost less than that value except that some results from group TS-1 \& TS-2 are slightly higher, indicating the test apparatus and the test procedure are effective and accurate for the study.

The repeatability is also revealed by the relations between hydraulic gradient and seepage velocity as shown in Fig. 6 . Clearly, variations in seepage velocity are experienced in three stages as the hydraulic gradient increases. At the beginning 
FIG. 6 Relations between seepage velocity and hydraulic gradient.

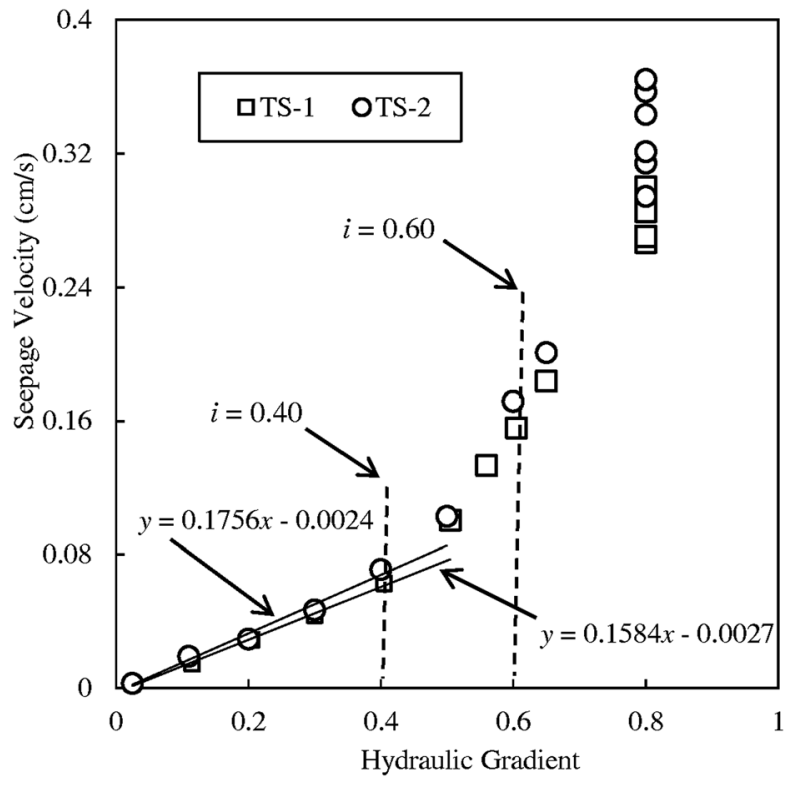

stage, the relations between the hydraulic gradient and the seepage velocity are linear, implying the intactness of the specimens and compliance with Darcy's law on seepage. At the second stage, the increase in seepage velocity begins to accelerate when the hydraulic gradient exceeds 0.40 . Visible eroded fine particles are observed in the outflow of the specimen when the hydraulic gradient reaches 0.60 in this stage. The third stage begins when the hydraulic gradient is increased to 0.80 . The specimens are eroded under the constant hydraulic gradient and the seepage velocity goes up gradually in this stage. The relation curves of the two tests are nearly identical in all three stages. The first stage indicates the initial permeability coefficients of the specimens. Using the Least Square Method, the fitted initial permeability coefficients of TS- 1 and TS-2 are 0.1584 and $0.1756 \mathrm{~cm} / \mathrm{s}$, respectively. The turning point, which corresponds to the hydraulic gradient equal to 0.4 for both tests between the first and second stages, is usually adopted as the CHG of the piping erosion (Chang and Zhang 2012; Fleshman and Rice 2013). Nevertheless, despite the hydraulic gradient exceeding the $\mathrm{CHG}$, there are few visible particles observed in the outflow of the specimen until the hydraulic gradient reaches 0.60 . The hydraulic gradient 0.60 is also regarded as a type of $\mathrm{CHG}$ (Chang and Zhang 2012). In the study, the CHG corresponding to the turning point of the relation between seepage velocity and hydraulic gradient is named the lower critical hydraulic gradient (LCHG). The LCHG is a critical state that a part of the fine particles in the specimen reaches their limit equilibrium of forces by the drag effect of flow water. The particles roll or move up and down in the pore of soil, but few particles loss unless the hydraulic gradient is further increased or the
FIG. 7 Influences of the stress state on the critical hydraulic gradient (TS-3: $p=10.0 \mathrm{kPa}, q=0.0 \mathrm{kPa}, W=1.854 \mathrm{~g} / \mathrm{cm}^{3} ; \mathrm{TS}-4: p=29.0 \mathrm{kPa}$, $q=27.0 \mathrm{kPa}, W=1.858 \mathrm{~g} / \mathrm{cm}^{3} ; \mathrm{TS}-5: p=43.3 \mathrm{kPa}, q=40.0 \mathrm{kPa}$, $\left.W=1.859 \mathrm{~g} / \mathrm{cm}^{3}\right)$.

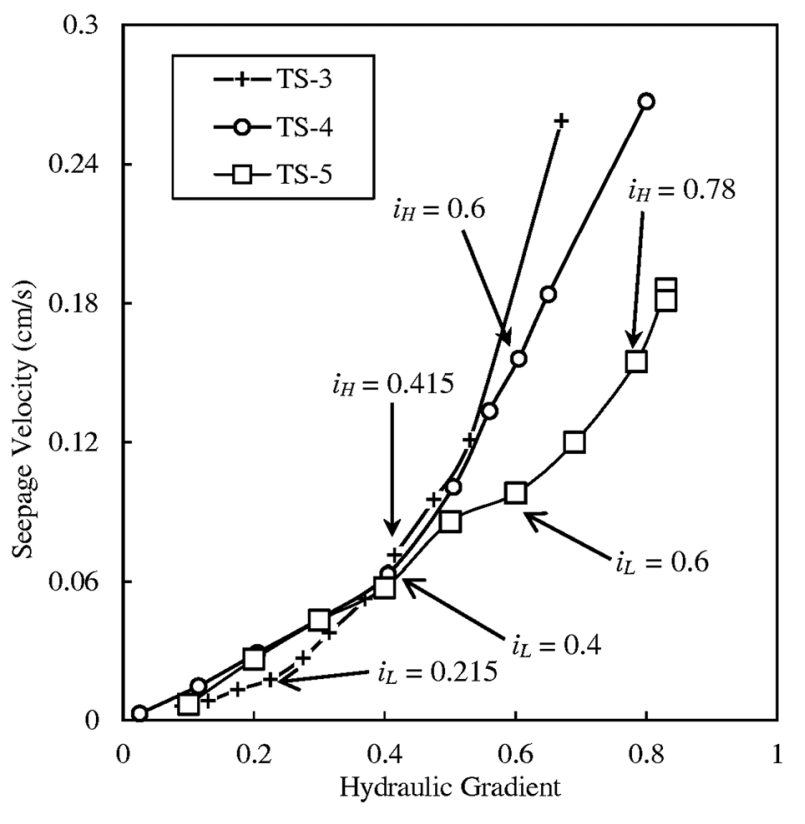

specimen is disturbed. So the LCHG is the lower limit for erosion, namely a gradient originates the erosion. The hydraulic gradient corresponding to the observation of continuously eroding of particles is named the high critical hydraulic gradient (HCHG). Thus, the HCHG is also a critical state indicating continuous seepage erosion. The LCHG and HCHG obtained in TS- 1 and TS- 2 are also coincident, which confirms the repeatability of the tests again.

\section{EFFECT OF STRESS STATE}

TS-3, TS-4, and TS-5 were carried out to assess the influences of stress state on erosion behavior. The confining stress in the three tests is $10.0,20.0$, and $30.0 \mathrm{kPa}$, respectively. The additional vertical pressure applied on top of the specimens is 0.0 , 27.0 , and $40.0 \mathrm{kPa}$, respectively. The corresponding stress states are listed in Table 2. To analyze the critical state of the erosion, the relations between seepage velocity and hydraulic gradient of the three tests are plotted in Fig. 7. According to the methodology used in Fig. 6, the LCHG acquired in TS-3, TS-4, and TS-5 is $0.215,0.4$, and 0.6 , respectively, whereas the HCHG is 0.415 , 0.6 , and 0.78 , respectively. Clearly, the CHG, no matter the LCHG or the HCHG, increases gradually as the effective mean stress and deviatoric stress increase, which is consistent with the studies carried out by Chang and Zhang (2012) and Tomlinson and Vaid (2000).

The influences of stress state on the particle erosion are also significant. The relation curves between the weight of the 
FIG. 8 Influences of the stress state on the particle erosion, from laboratory tests (dots; TS-3: $i=0.77$; TS- $4: i=0.78$; and TS- $5: i=0.83$ ) and from data fitting with Eq 5 (solid lines; B and $C$ are constants in Eq 5, and $R^{2}$ is coefficient of determination).

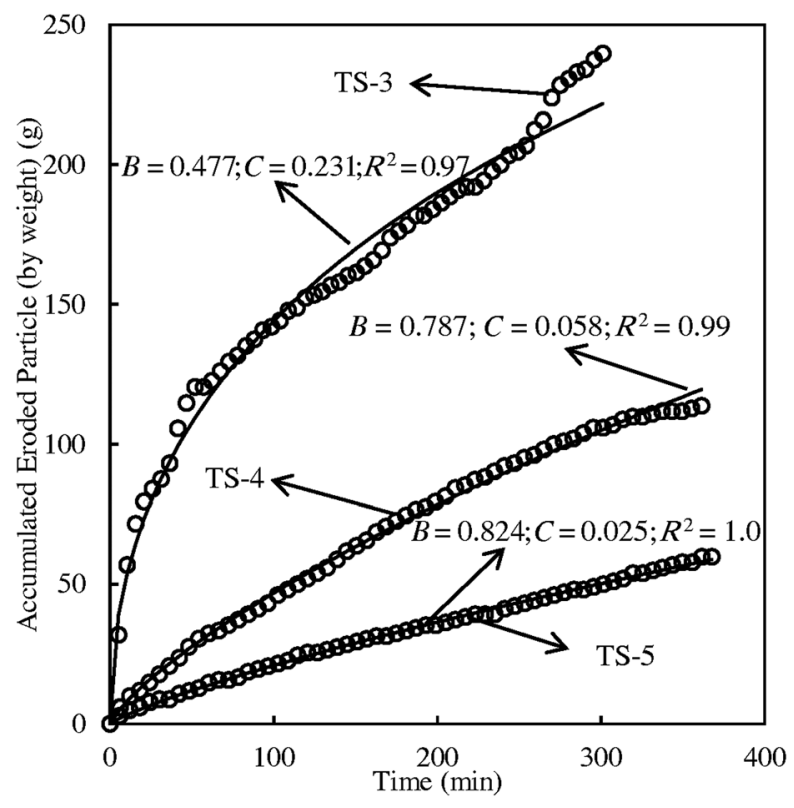

accumulated eroded particles and the erosion time are plotted in Fig. 8. The data in the figure are collected by the water-soil seperating system. The hydraulic gradients, $0.77,0.78$, and 0.83 for TS-3, TS-4, and TS-5, respectively, are nearly equal in spite of the inevitable experimental error. Regarding the erosion procedure, the quantity of accumulated eroded particles increases gradually with the erosion time for the three tests, an outcome similar to the results in the analysis of repeatability tests. The amount of erosion particles also decreases obviously even under the same hydraulic gradient when a high stress is applied to the specimen, meaning the outer pressure obstructs the escape of fine particles from the original soil. The negative effect on particle erosion of the outer pressure is mainly attributed to the enhanced constraint between particles because of the confining stress and vertical stress applied.

\section{EFFECT OF HYDRAULIC GRADIENT}

Four tests, TS-4, TS-6, TS-7, and TS-8, under the same stress state condition are carried out to explore the influences of hydraulic gradient on the erosion behavior. Four hydraulic gradients, $0.78,0.88,0.98$, and 1.08 , are utilized in the four tests, respectively. The data on the amount of the eroded particles are plotted in Fig. 9. The erosion, that is, both the erosion amount and the erosion rate, is revealed to be enhanced by the increasing hydraulic gradient. The amount of eroded particles in TS- 6 surpasses that in TS- 4 under the same erosion time, revealing that the enhancement of hydraulic gradients increases from 0.78 to 0.88 to some degree. The research carried out by Sterpi
FIG. 9 Influences of the hydraulic gradient on the particle erosion (Effective Mean Stress $=29 \mathrm{kPa}$, Deviatoric Stress $=27 \mathrm{kPa}$ ).

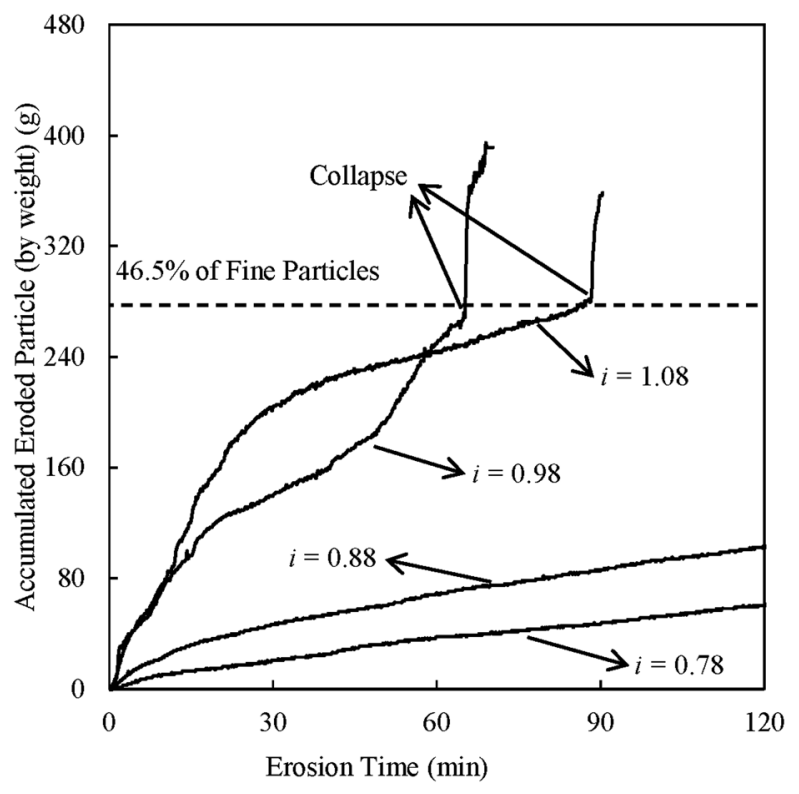

(2003) also supports this type of hydraulic gradient effect. Based on the research, a nonlinear incremental law was proposed to describe the relations between the amount of eroded fine particles and the erosion time. Incremental law believes the amount of eroded fine particles increases smoothly with erosion time and tends to reach a stable value when most of the fine particles in the soil are eroded. The nonlinear incremental law proposed by Sterpi (2003) is

$$
\mu=\mu_{0}\left[1-e^{-C\left(\frac{t}{60}\right)^{B}}\right]
$$

where:

$\mu=$ weight of eroded fine particles,

$\mu_{0}=$ initial weight of fine particles, which is equal to $580 \mathrm{~g}$ calculated from the PSD and dry density,

$B$ and $C=$ constants, and

$t=$ erosion time.

With the least square method (LSM), data in Fig. 8 can be fitted with Eq 5. The fitting results are also plot in the figure. It shows that the expected outcome is approximately concordant with the test results with low hydraulic gradients. Though this empirical equation works well in data fitting in Fig. 8, it is limited to describe the long-term erosion law. The initial weight of fine particles, $\mu_{0}$, is an asymptotic value in Eq 5, indicating that the fine particles will tend to be totally eroded in the end of the erosion. However, it is doubtless that some fine particles will remained in the soil especially when the hydraulic gradient is relatively low. Cividini et al. (2009) revealed that the long term quantity of the remained fine particles, equal to $\mu_{0}$ in this study, would decrease with increasing hydraulic gradient. So, Eq 5 will 
FIG. 10 Comparison of the specimen before and after collapsing (TS-7): (a) before collapsing and (b) after collapsing.

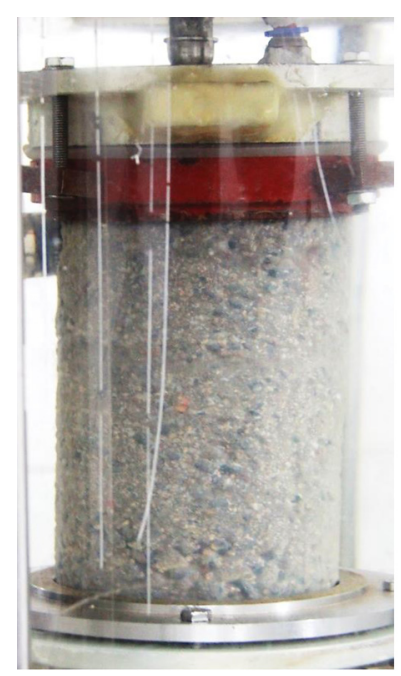

(a)

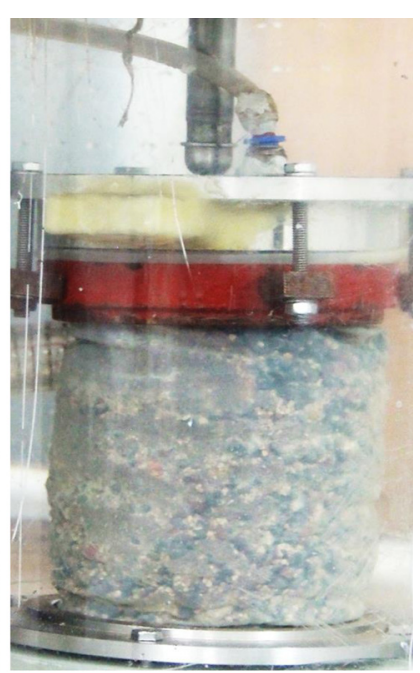

(b) be more effective if the relationship between the parameter $\mu_{0}$ and the hydraulic gradient is employed.

A significant difference to the traditional understanding of erosion law is observed in the study when the hydraulic gradient is relatively high, such as 0.98 and 1.08 in TS-7 and TS-8, respectively. The amount of eroded particles in TS-7 and TS- 8 increases gradually at the beginning of the erosion, similar to the results of other tests. However, once the erosion time reaches a particular value, about $65.0 \mathrm{~min}$ in TS-7, for example, the erosion rate abruptly increases and the specimen collapses owing to a huge volumetric deformation in a short time. A comparison of the specimen before and after the collapse of TS-7 is shown in Fig. 10. The erosion procedure of TS- 8 is similar to that of TS-7, except for a little delay in collapse time. The comprehensive analysis of the erosion curves of TS-7 and TS- 8 also reveals that the collapses of the two tests are associated with the same amount of eroded particles, which is about $270.0 \mathrm{~g}$. The total quantity of fine particles in a specimen is solved by combining the dry density and PSD of the specimen, which is about $580.0 \mathrm{~g}$. Hence, the collapse of the specimen can be predicted once $46.5 \%$ of fine particles are eroded. A study carried out by Chang and Zhang (2012) also revealed similar results, and the collapse was regarded as the failure stage of the erosion, and attributed the collapsing to the increasing hydraulic gradient. However, the results in this study reveals that the quantity of the eroded particles is also a vital factor besides the hydraulic gradient. When the hydraulic gradient is increased to the HCHG or even higher, fine particles around the skeleton particles begin to be eroded. However, the skeleton structure of soil remains stable, and then the volumetric deformation is resulted from the particles loss solely. In terms of the research of Sterpi (2003), some fine particles are inevitably left in the soil. But the quantity of eroded particles will increase with the increasing hydraulic gradient and erosion time. If the soil is constantly eroded, the skeleton structure loses the retaining of the fine particles around it, indicating the force chains in the coarse particles lose effectiveness. Then the coarse particles begin to move and fill into the pores generated by fine particles erosion. Consequently, the volume of the soil will instantly shrink, and more fine particles are released and eroded as the relocation of the coarse particles, namely the collapsing of soil. Inversely, if the fine particles left surrounding the course particles are enough to retain the skeleton structure, the collapsing will not occur, such as the tests conducted by Sterpi (2003) and some other researches on suffusion. The effects of other factors such as the composition of soils and the stress state need to be further explored as well.

The test results shown above indicate that a whole testing process in the study may be divided into three or four phases in terms of the summary of the erosion procedure above. The first phase is from the beginning of the test to the reaching of the low CHG of piping erosion. The hydraulic head and the hydraulic gradient applied to the specimen increase gradually in this phase, but the static equilibrium of the particles in the specimen is still maintained since the seepage force is relatively low. This outcome is responsible for the intactness of the specimen in the phase because no particle is flowing out. Thus, the seepage flux increases with the rising in hydraulic gradient. The second phase ranges between the times the low and high CHGs are applied. In this phase, no apparent eroded particles are observed flow out of the specimen, while the permeability of the specimen increases slightly. The third phase begins with the observation of continuously eroded particles and ends at the time before the collapse. Particles are gradually eroded in this phase, in which the eroded fine particles are continuously brought out of the specimen by water flow. The seepage velocity increases with the particle erosion, which can be concluded by the water quantity entering the downstream water tank. The specimen deforms with the particle loss, but the deformation is relatively small. The existence of the fourth phase depends on the collapse of the specimen. This phase lasts briefly, such that abundant fine particles are rushed out of the specimen with rapidly flowing water. The permeability increases significantly, and the specimen fails in a very short time.

\section{Conclusions}

In this study, piping erosion in an upward flow is investigated using a new designed apparatus. The apparatus is stress controlled and capable of testing the upward piping behavior of cohesionless soil. Complex stress states can be applied on the specimen via the independent confining stress and vertical 
stress loading system of the apparatus. The soil-water separating system can monitor the amount of the erosion particles continuously. A wired hose is used to connect the export of the cap of the specimen and the soil-water separating system to avoid disturbing vertical deformation on the vertical loading. In the test schedule, the hydraulic gradient is maintained at some constant values beyond the critical value to assess its influences on erosion behavior. A series of tests is conducted to evaluate and analyze the repeatability of the apparatus and the test schedule, the $\mathrm{CHG}$, the erosion law, and the effect of stress state and hydraulic gradient on erosion behaviors, from which some significant conclusions can be drawn as follows:

1. The apparatus and the test schedule have high-level repeatability based on the comparison of parallel tests. The results from parallel tests reveal the erosion behavior under a certain stress state. A lower CHG and a high CHG are proposed, respectively, in terms of the relations between seepage velocity and hydraulic gradient. The amount of eroded particles gradually increases in the erosion procedure.

2. The effects of stress state on the CHG and the particle erosion rate are prominent. The test results show that outer pressure on the specimen is an obstacle to the occurrence and development of erosion. The erosion procedure is also remarkably related to the hydraulic gradient. Additionally, the erosion law will deviate from the traditional empirical formula if the hydraulic gradient is relatively high. A critical eroded proportion of fine particles, which is $46.5 \%$ in the study, is proposed in the erosion procedure. The collapse of the specimen will occur when the amount of eroded fine particles exceeds the critical proportion.

\section{ACKNOWLEDGMENTS}

The writers acknowledge the financial supports from the Natural Science Foundation of China (51409029 and 51479014), the China Postdoctoral Science Foundation (2014M562288), the Chongqing Science \& Technology Commission of China (cstc2013jcyjA30006), and the Chongqing Education Commission of China (KJ130412).

\section{References}

Bligh, W. G., 1910, "Dams, Barrages and Weirs on Porous Foundations," Eng. News, Vol. 64, No. 26, pp. 708-710.

Bligh, W., 1913, "Lessons From the Failure of a Weir and Sluices on Porous Foundations," Eng. News, Vol. 69, No. 6, pp. 266-270.

Chang, D. S. and Zhang, L. M., 2011, "A Stress-Controlled Erosion Apparatus for Studying Internal Erosion in Soils," Geotech. Test. J., Vol. 34, No. 6, pp. 579-589, http:// dx.doi.org/10.1520/GTJ103889

Chang, D. S. and Zhang, L. M., 2012, "Critical Hydraulic Gradients of Internal Erosion Under Complex Stress States," J. Geotech. Geoenviron. Eng., Vol. 139, No. 9, pp. 1454-1467, http://dx.doi.org/10.1061/(ASCE)GT.19435606.0000871

Chang, D. S. and Zhang, L. M., 2013, "Extended Internal Stability Criteria for Soils Under Seepage," Soils Found., Vol. 53, No. 4, pp. 569-583, http://dx.doi.org/10.1016/j.sandf.2013. 06.008

Cividini, A., Bonomi, S., Vignati, G. C., and Gioda, G., 2009, "Seepage-Induced Erosion in Granular Soil and Consequent Settlements," Int. J. Geomech., Vol. 9, No. 4, pp. 187-194, http://dx.doi.org/10.1061/(ASCE)1532-3641 (2009)9:4(187)

Cividini, A. and Gioda, G., 2004, "Finite-Element Approach to the Erosion and Transport of Fine Particles in Granular Soils," Int. J. Geomech., Vol. 4, No. 3, pp. 191-198, http:// dx.doi.org/10.1061/(ASCE)1532-3641(2004)4:3(191)

Das, B. M., 2013, Advanced Soil Mechanics, CRC Press, Boca Raton, FL.

Fleshman, M. S. and Rice, J. D., 2013, "Constant Gradient Piping Test Apparatus for Evaluation of Critical Hydraulic Conditions for the Initiation of Piping," Geotech. Test. J., Vol. 36, No. 6, pp. 834-846, http://dx.doi.org/10.1520/ GTJ20130066

Fleshman, M. S. and Rice, J. D., 2014, "Laboratory Modeling of the Mechanisms of Piping Erosion Initiation," J. Geotech. Geoenviron. Eng. Vol. 140, No. 6, http://dx.doi.org/10.1061/ (ASCE)GT.1943-5606.0001106

Foster, M., Fell, R., and Spannagle, M., 2000, "The Statistics of Embankment Dam Failures and Accidents," Can. Geotech. J., Vol. 37, No. 5, pp. 1000-1024, http://dx.doi.org/10.1139/ t00-030

Indraratna, B. and Radampola, S., 2002, "Analysis of Critical Hydraulic Gradient for Particle Movement in Filtration," J. Geotech. Geoenviron. Eng., Vol. 128, No. 4, pp. 347-350, http://dx.doi.org/10.1061/(ASCE)1090-0241 (2002)128:4(347)

Indraratna, B. and Vafai, F., 1997, “Analytical Model for Particle Migration Within Base Soil-Filter System," J. Geotech. Geoenviron. Eng., Vol. 123, No. 2, pp. 100-109, http:// dx.doi.org/10.1061/(ASCE)1090-0241(1997)123:2(100)

Kovacs, G., 1981, Seepage Hydraulics, Elsevier Scientific Publishing Company, New York.

Lane, E., 1934, "Security From Under-Seepage Masonry Dams on Earth Foundations," Trans. Am. Soc. Civ. Eng., Vol. 100, No. 1, pp. 1235-1272.

Liang, Y., Wang, J., and Liu, M., 2013, "Two-Flow Model for Piping Erosion Based on Liquid-Solid Coupling," J. Central South Univ., Vol. 20, No. 8, pp. 2299-2306, http:// dx.doi.org/10.1007/s11771-013-1737-y

Luo, Y., Chen, L., Xu, M., and Huang, J., 2014, "Breaking Mode of Cohesive Homogeneous Earth-Rock-Fill Dam by Overtopping Flow," Nat. Haz., Vol. 74, No. 2, pp. 527-540, http://dx.doi.org/10.1007/s11069-014-1202-8

Luo, Y., Qiao, L., Liu, X., Zhan, M., and Sheng, J., 2013a, "Hydro-Mechanical Experiments on Suffusion Under Long-Term Large Hydraulic Heads," Nat. Haz., Vol. 65, No. 3, pp. 1361-1377, http://dx.doi.org/10.1007/s11069-0120415-y

Luo, Y., Xi, J., and Li, X., 2013b, “A New Apparatus for Evaluation of Contact Erosion at the Soil-Structure Interface," Geotech. Test. J., Vol. 36, No. 2, pp. 256-263, http://dx.doi.org/ 10.1520/GTJ20120094 
Moffat, R. A. and Fannin, R. J., 2006, "A Large Permeameter for Study of Internal Stability in Cohesionless Soils," Geotech. Test. J., Vol. 29, No. 4, pp. 1-7, http://dx.doi.org/10.1520/ GTJ100021

Richards, K. S. and Reddy, K. R., 2007, "Critical Appraisal of Piping Phenomena in Earth Dams," Bull. Eng. Geol. Environ., Vol. 66, No. 4, pp. 381-402, http://dx.doi.org/10.1007/ s10064-007-0095-0

Richards, K. S. and Reddy, K. R., 2010, “True Triaxial Piping Test Apparatus for Evaluation of Piping Potential in Earth Structures," Geotech. Test. J., Vol. 33, No. 1, pp. 83-95, http://dx.doi.org/10.1520/GTJ102246

Richards, K. S. and Reddy, K. R., 2012, "Experimental Investigation of Initiation of Backward Erosion Piping in Soils," Géotechnique, Vol. 62, No. 10, pp. 933-942, http:// dx.doi.org/10.1680/geot.11.P.058

Skempton, A. W. and Brogan, J. M., 1994, "Experiments on Piping in Sandy Gravels," Géotechnique, Vol. 44, No. 3, pp. 449-460, http://dx.doi.org/10.1680/geot.1994.44.3.449

Sterpi, D., 2003, "Effects of the Erosion and Transport of Fine Particles Due to Seepage Flow," Int. J. Geomech., Vol. 3,
No. 1, pp. 111-122, http://dx.doi.org/10.1061/(ASCE)15323641(2003)3:1(111)

Terzaghi, K. V., 1922, "Der Grundbruch an Stauwerken und Seine Verhuetung ['Soil Failure at Barrages and Its Prevention'],” Die Wasserkraft, Vol. 17, No. 24, pp. 445-449.

Tomlinson, S. S. and Vaid, Y. P., 2000, "Seepage Forces and Confining Pressure Effects on Piping Erosion," Can. Geotech. J., Vol. 37, No. 1, pp. 1-13, http://dx.doi.org/10.1139/t99-116

Wan, C. and Fell, R., 2004a, "Investigation of Rate of Erosion of Soils in Embankment Dams," J. Geotech. Geoenviron. Eng., Vol. 130, No. 4, pp. 373-380, http://dx.doi.org/10.1061/ (ASCE) 1090-0241(2004)130:4(373)

Wan, C. F. and Fell, R., 2004b, "Laboratory Tests on the Rate of Piping Erosion Of Soils in Embankment Dams," Geotech. Test. J., Vol. 27, No. 3, pp. 295-303, http://dx.doi.org/ 10.1520/GTJ11903

Wan, C. and Fell, R., 2008, "Assessing the Potential of Internal Instability and Suffusion in Embankment Dams and Their Foundations," J. Geotech. Geoenviron. Eng., Vol. 134, No. 3, pp. 401-407, http://dx.doi.org/10.1061/(ASCE)1090-0241 (2008)134:3(401) 